\title{
Systemic Amyloidosis in a Patient with Type 2 Diabetes Mellitus as a Uncommon Cause of Non-Diabetic Renal Disease
}

\author{
Ying-Ying Gong ${ }^{2 \#}$, Lei Sü ${ }^{2 \#}$, Min Lin ${ }^{1}$, Jin $\mathrm{Li}^{2}$, Mei-lin Ding ${ }^{2}$ and Hai-peng Xiao ${ }^{1 *}$
}

${ }^{1}$ Department of Endocrinology, The First Affiliated Hospital of Sun Yat-sen University, Guangzhou, 510080 China

${ }^{2}$ Department of Geriatrics, The First Affiliated Hospital of Sun Yat-Sen University, Guangzhou, 510080 China

\#These authors contributed equally to this work

\begin{abstract}
Background: The incidence of non-diabetic renal disease is very high in type 2 diabetic patients. Systemic amyloidosis as one of the non-diabetic renal disease rarely occur in type 2 diabetes mellitus subjects and may have the high risk of early mortality.

Case report and management: We report a case in a 66-year-old patient with legs edema, inappetence and frothy urine for 2 weeks. The patient was diagnosed type 2 diabetes on routine testing 10 years ago without any symptoms. The blood glucose was adequately controlled with diet and exercise. Physical examination showed edema of lower extremities and hepatomegaly. $24 \mathrm{hrs}$ urinary protein was $4.7 \mathrm{~g}$. Blood investigation showed slightly impaired liver function while other results incluing serological studies and bone marrow aspirate showed negative or in normal range. Funduscopy showed normal retinal blood vessels and optic disc. Echocardiography revealed cardiac amyloidosis with septal hypertrophy and the ultrasound scan revealed hepatomegaly. Hepatic biopsy was performed and diagnosis of systemic amyloidosis was made due to positive congo red staining.
\end{abstract}

Conclusions: When massive proteinuria occurred in patient with type 2 diabetes and other internal organs like liver and heart are affected, superimposed systemic amyloidosis should be considered in particular.

Keywords: Non-diabetic renal disease; Primary systemic amyloidosis; Type 2 diabetes mellitus; Hepatic biopsy

Abbreviations: DN: Diabetic nephropathy; NDRD: Non-diabetic Renal Disease; ALT: Alanine Aminotransferase; AST: Aspartate Aminotransferase; T2DM; Type 2 Diabetes Mellitus

\section{Introduction}

It is estimated that about $20 \%-40 \%$ of patients with type 1 or type 2 diabetes will develop diabetic nephropathy (DN), which contributes to most end-stage renal disease worldwide [1,2]. Diagnosis of DN is mostly clinically based on a long history of diabetes, proteinuria, hypertension, and a progressive decline in renal function. This diagnostic approach is inconclusive, due to the fact that non-diabetic renal disease (NDRD) has been found in type 2 diabetes mellitus (T2DM) patients. The prevalence of NDRD in type 2 diabetic patients with renal involvement varies from $20-80 \%$ [3-6]. The diagnose of NDRD in diabetic patients has an obvious prognostic and therapeutic importance. The common NDRD includes glomerulonephritides, vascular nephropathy, cholesterol microembolism and so on. Systemic amyloidosis is a rare disease with an incidence of 4.5 per 100000 person-years [7]. The pathological production of fibrillar proteins can deposit in numerous tissues and cause organ dysfunction including kidney, liver, heart, lung, spleen, gastrointestinal tract and bladder. Here, we describe a rare case of type 2 diabetes presenting with massive proteinuria due to primary systemic amyloidosis.

\section{Case Presentation}

A 66-year-old male was admitted on March 2014, presenting with edema of legs, in appetence and frothy urine for 2 weeks. He was diagnosed type 2 diabetes on routine testing 10 years ago without any symptoms. The diagnosis was based on the fasting glucose which shown $7.0 \mathrm{mmol} / \mathrm{L}$ and $7.1 \mathrm{mmol} / \mathrm{L}$ respectively on two occasions. The blood glucose was adequately controlled with diet and exercise for the first few years with HbAlc around 6.5\%. However, in the last 4 years, he did not have any self-monitoring or go for a routine clinical consultation. The most recent fasting glucose was $10.8 \mathrm{mmol} / \mathrm{L}$. There was no history of diabetic retinopathy or neuropathy. He denied family history of diabetes or systemic disease. His vitals displayed blood pressure of $107 / 66 \mathrm{mmHg}$. Pulse rate was $64 /$ minute. His liver was palpable by $5 \mathrm{~cm}$ below the right costal margin. The rest of physical examination showed mild edema of lower extremities. Laboratory investigation revealed hemoglobin $117 \mathrm{~g} / \mathrm{L}$, serum creatinine 101 $\mu \mathrm{mol} / \mathrm{L}$, albumin $30.6 \mathrm{~g} / \mathrm{L}$, fasting blood glucose $9.6 \mathrm{mmol} / \mathrm{L}$, uric acid $550 \mu \mathrm{mol} / \mathrm{L}$. Urinalysis showed no dysmorphic erythrocytes, cellular casts, or crystals with $24 \mathrm{hrs}$ urinary protein of $4.7 \mathrm{~g}$. Quantitative immunoglobulins and serological studies including anti-nuclear antibody, anti-dsDNA, anti-neutrophil cytoplasmic antibody, antigluomerular basement antibodies, complement levels $(\mathrm{C} 3, \mathrm{C} 4)$ and HIV, HBsAg, Anti HCV, Anti-CMV antibodies were all within the reference ranges. The synthetic liver function impaired slightly, such as alanine aminotransferase (ALT) at $132 \mathrm{IU} / \mathrm{L}$, aspartate aminotransferase (AST) with TBIL $28.2 \mu \mathrm{mol} / \mathrm{L}$ (Table 1). Until now, the clinical diagnosis of nephrotic syndrome was made. However, whether the nephrotic syndrome was associated with type 2 diabetes was doubtful. Urine immunofixation found free $\lambda$ Bence-Jones protein.

*Corresponding author: Hai-peng Xiao, Department of Endocrinology, The First Affiliated Hospital of Sun Yat-sen University, 58 Zhongshan Road 2, Guangzhou 510080 P.R. China. Tel: +862087755776-8803; Fax: +862087330736; E-mail: xiaohp@mail.sysu.edu.cn

Received September 30, 2014; Accepted March 16, 2015; Published March 19 2015

Citation: Gong YY, Su L, Lin M, Li J, Ding Ml, et al. (2015) Systemic Amyloidosis in a Patient with Type 2 Diabetes Mellitus as a Uncommon Cause of Non-Diabetic Renal Disease. J Diabetes Metab 6: 528. doi:10.4172/2155-6156.1000528

Copyright: $\odot 2015$ Gong YY, et al. This is an open-access article distributed unde the terms of the Creative Commons Attribution License, which permits unrestricted use, distribution, and reproduction in any medium, provided the original author and source are credited. 


\begin{tabular}{|c|c|c|c|c|}
\hline Data & Result & Normal range & Data & Result \\
\hline hemoglobin & $117 \mathrm{~g} / \mathrm{L}$ & $120-160$ & occult blood (urine) & $(-)$ \\
\hline creatinine & $101 \mu \mathrm{mol} / \mathrm{L}$ & $53-115$ & sugar (urine) & $(-)$ \\
\hline albumin & $30.6 \mathrm{~g} / \mathrm{L}$ & $35.0-50.0$ & protein (urine) & $3+$ \\
\hline TP & $55.0 \mathrm{~g} / \mathrm{L}$ & $64.0-87.0$ & granular casts (urine) & $(-)$ \\
\hline globulin & $22.3 \mathrm{~g} / \mathrm{L}$ & $20.0-32.0$ & urinary protein & $4.7 \mathrm{~g} / 24 \mathrm{hrs}$ \\
\hline FBG & $9.6 \mathrm{mmol} / \mathrm{L}$ & $2.9-6.0$ & HbA1c & $6.2 \%$ \\
Uric acid & $550 \mu \mathrm{mol} / \mathrm{L}$ & $200-430$ & ESR & $9 \mathrm{~mm} / \mathrm{h}$ \\
\hline TG & $9.41 \mathrm{mmol} / \mathrm{L}$ & $0.33-1.70$ & ANCA & $(-)$ \\
\hline IgA & $2.90 \mathrm{~g} / \mathrm{L}$ & $1.45-3.45$ & ANA & $(-)$ \\
\hline IgM & $0.46 \mathrm{~g} / \mathrm{L}$ & $0.92-2.04$ & ds-DNA & $(-)$ \\
\hline IgG & $6.63 \mathrm{~g} / \mathrm{L}$ & $10.13-15.13$ & HIV antibody & $(-)$ \\
\hline SAA & $109 \mathrm{mg} / \mathrm{L}$ & $1.00-6.40$ & HbsAg & $(-)$ \\
\hline $\mathrm{C} 3$ & $0.91 \mathrm{~g} / \mathrm{L}$ & $0.79-1.17$ & HCV antibody & $(-)$ \\
\hline C4 & $0.24 \mathrm{~g} / \mathrm{L}$ & $0.17-0.31$ & Anti-GBM antibody & $(-)$ \\
\hline ALT & $161 \mathrm{U} / \mathrm{L}$ & $1-40$ & CMV antibody & $(-)$ \\
\hline AST & $132 \mathrm{U} / \mathrm{L}$ & $1-37$ & Urine immunofixation & Bence-Jones \\
\hline LDH & $282 \mathrm{U} / \mathrm{L}$ & $114-240$ & & protein free $\lambda$ \\
\hline TBIL & $28.2 \mu \mathrm{mol} / \mathrm{L}$ & $3.0-22.0$ & Serum protein & $(-)$ \\
\hline ProBNP & $837.9 \mathrm{pg} / \mathrm{mL}$ & $<84$ & electrophoresis & \\
\hline
\end{tabular}

Abbreviations: TP: total protein; FBG: fasting blood glucose; SAA: serum amyloid A TG: triglyceride; AST: Aspartate Aminotransferase; ALT: Alanine Aminotransferase LDH: Lactate Dehydrogenase; TBIL: Total Bilirubin; HbA1c: Hemoglobin A1c ESR: Erythrocyte Sedimentation Rate; ANCA: Myeloperoxidase Anti-neutrophil Cytoplasmic Antibodies; ANA: Anti nuclear Antibody; HCV: Hepatitis C Virus; CMV: Cytomegalovirus; GBM: Glomerular Basement Membrane

Table 1: Laboratory Data on Admission

Serum protein electrophoresis revealed no evidence of monoclonal proteins. To exclude multiple myeloma, a bone marrow aspirate was performed. The plasma cells were found at $4 \%$ with typically $96.6 \%$ of CD56, $8.5 \%$ of $\kappa, 91.5 \%$ of $\lambda$ by flow cytometry.

Normal retinal blood vessels and optic disc were observed under funduscopy suggesting the absence of retinopathy. Electrocardiogram showed frequent multifocal ventricular premature beats and low voltage. Echocardiography revealed septal hypertrophy $(13 \mathrm{~mm})$ and thickening of left ventricular and right ventricular posterior wall (left ventricular posterior wall was $13 \mathrm{~mm}$ ). It also showed expansion of both atriums (left atrial diameter: $40 \mathrm{~mm}$, right atrial diameter: $62 \mathrm{~mm} \times 43$ $\mathrm{mm}$ ) with un-even enhanced myocardial echo. The cardiac valves were normal and LVEF was $60 \%$. A small area of pericardial effusion was found. Ultrasound showed hepatomegaly (the diameter of right lobe was $22 \mathrm{~cm}$ ) with homogeneous echo. Percutaneous hepatic biopsy was performed for diagnosis which revealed amyloid deposits in hepatic sinusoids with positive Congo red staining and kappa (-), lambda (-), CD56 (-). So far systemic amyloidosis was diagnosed. The patient refused further chemotherapy and started to treat with sitagliptin (100 $\mathrm{mg} /$ day) along with losartan $(50 \mathrm{mg} /$ day). Interestingly, he suffered orthostatic hypotension with a fall blood pressure at $80 / 50 \mathrm{mmHg}$ after an upright position while the supine blood pressure at 110/70 mmHg. So, he stopped taking the losartan. Six months after the initial diagnosis, the patient was still alive but presented with poor condition.

\section{Discussion}

Diabetic nephropathy is a complication of diabetes associated with the kidney which could progressively lead to end-stage renal diseases [2]. The diagnosis of $\mathrm{DN}$ is frequently based on clinical characterization exclusively. Actually, a variety of NDRDs are often overlooked in diabetic patients, which have significant impacts on prognosis and treatment. The challenges still exist to differentiate NDRD from DN in diabetic patients. Therefore, renal biopsy is the only tool to diagnose NDRD. However, the renal biopsy cannot be used as a routine diagnostic test in type 2 diabetic patients with proteinuria because of the invasiveness. Therefore, the main indication for renal biopsy was clinically thorough suspicion of NDRD. The common indications for NDRD in type 2 diabetes are short duration of type 2 diabetes, acute or rapidly progressive renal failure, glomerular hematuria, absence of diabetic retinopathy, nephritic syndrome with normal renal function $[3,8,9]$. As in our case, despite the patients having T2DM for more than 10 years, high level of proteinuria without retinopathy suggests a diagnosis of NDRD other than DN. Thus, biopsy was considered in our patient for the precise diagnosis.

A wide spectrum of NDRNs reported in patients with type 2 diabetes mainly include glomerular and tubulointestinal lesions [1012]. In our case, we diagnosed the systemic amyloidosis which is an infrequent cause of non-diabetic renal disease in patient with type 2 diabetes based on positive Congo red staining. Systemic amyloidosis is a rare and severe disease which involves several organs including kidney, liver, heart, lung, spleen, gastrointestinal tract, bladder and endocrine system and leads to a high motality rate $[13,14]$. Without treatment, the median survival is less than 6 months [15]. For all newly diagnosed cases of amyloidosis, an assessment of the specific type of amyloid is critical in ensuring proper therapy. In our case, free $\lambda$ Bence-Jones protein was found in urine immunofixation. But the histochemical staining revealed negative kappa and lambda. Thus, the type of amyloid is needed further confirmed by using polymerase chain reaction amplification and sequencing of mutated genes. Based on the examination, our patient presented with multiorgan affected like liver and heart. Renal disease as a frequent manifestation of the systemic amyloidosis usually cause proteinuric renal failure in the context of normal or low blood pressure. Interestingly, despite taking the small dose of losartan, our patient had developed orthostatic hypotension. It is indicated that autonomic nervous may be affected. Prognosis is determined by the number and severity of involved internal organ, the heart involvement in particular [16]. Left atrial enlargement is proved as an independent predictor of total long-term survival [17].
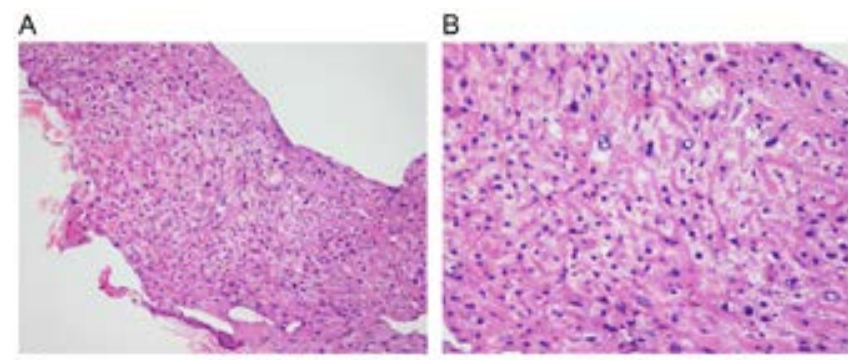

C

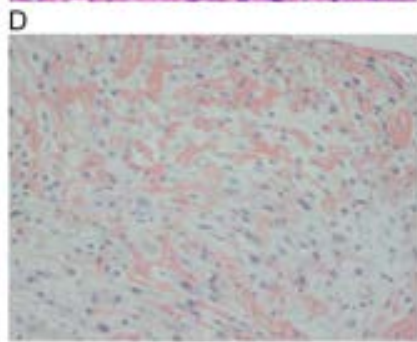

Figure 1: A liver-biopsy specimen stained with Hematoxylin and eosin $\times 200$ (A); $\times 400$ (B) shows a eosinophilic amorphous material deposits in hepatic sinus. The Congo staining reveals amyloid deposits in the hepatic sinus $\times 200(C) ; \times 400(D)$. 
Citation: Gong YY, Su L, Lin M, Li J, Ding Ml, et al. (2015) Systemic Amyloidosis in a Patient with Type 2 Diabetes Mellitus as a Uncommon Cause of Non-Diabetic Renal Disease. J Diabetes Metab 6: 528. doi:10.4172/2155-6156.1000528

Page 3 of 3

In our case, echocardiography showed expansion of both atrium and left ventricle with enhanced myocardial echo which strongly suggested the cardiac amyloidosis. Base on the multiorgan involvement with laboratory measurements and additional examination especially the cardiac parameter, we identify that our patient with highest risk of early mortality (Figure 1).

\section{Conclusion}

When a patient of type 2 diabetes presents proteinuria and exhibits several organs involvement like liver and heart, systemic amyloidosis should be considered rather than diabetic nephropathy.

\section{Acknowledgments}

We thank Dr Yuan Ling (Department of pathology, the First Affiliated Hospital of Sun Yat-sen University) for performing the immunohistochemical imaging.

\section{References}

1. Kikkawa R, Koya D, Haneda M (2003) Progression of diabetic nephropathy. Am J Kidney Dis 41: S19-21.

2. ESRD Incidence Study Group, Stewart JH, McCredie MR, Williams SM (2006) Geographic, ethnic, age-related and temporal variation in the incidence of endstage renal disease in Europe, Canada and the Asia-Pacific region, 1998-2002. Nephrol Dial Transplant 21: 2178-2183.

3. Tone A, Shikata K, Matsuda M, Usui H, Okada S, et al. (2005) Clinical features of non-diabetic renal diseases in patients with type 2 diabetes. Diabetes Res Clin Pract 69: 237-242

4. Richards NT, Greaves I, Lee SJ, Howie AJ, Adu D, et al. (1992) Increased prevalence of renal biopsy findings other than diabetic glomerulopathy in type Il diabetes mellitus. Nephrol Dial Transplant 7: 397-399.

5. Prakash J, Sen D, Usha, Kumar NS (2001) Non-diabetic renal disease in patients with type 2 diabetes mellitus. J Assoc Physicians India 49: 415-420.
6. Schwartz MM, Lewis EJ, Leonard-Martin T, Lewis JB, Batlle D (1998) Renal pathology patterns in type II diabetes mellitus: relationship with retinopathy. The Collaborative Study Group. Nephrol Dial Transplant 13: 2547-2552.

7. Merlini G, Stone MJ (2006) Dangerous small B-cell clones. Blood 108: 2520 2530.

8. Zhou J, Chen X, Xie Y, Li J, Yamanaka N, et al. (2008) A differential diagnostic model of diabetic nephropathy and non-diabetic renal diseases. Nephrol Dial Transplant 23: 1940-1945.

9. Christensen PK, Larsen S, Horn T, Olsen S, Parving HH (2000) Causes of albuminuria in patients with type 2 diabetes without diabetic retinopathy. Kidney Int 58: 1719-1731.

10. Kasinath BS, Mujais SK, Spargo BH, Katz Al (1983) Nondiabetic renal disease in patients with diabetes mellitus. Am J Med 75: 613-617.

11. Zhuo L, Ren W, Li W, Zou G, Lu J (2013) Evaluation of renal biopsies in type 2 diabetic patients with kidney disease: a clinicopathological study of 216 cases. Int Urol Nephrol 45: 173-179.

12. Pham TT, Sim JJ, Kujubu DA, Liu IL, Kumar VA (2007) Prevalence of nondiabetic renal disease in diabetic patients. Am J Nephrol 27: 322-328.

13. Ozdemir D, Dagdelen S, Erbas T (2010) Endocrine involvement in systemic amyloidosis. Endocr Pract 16: 1056-1063.

14. Obici L, Perfetti V, Palladini G, Moratti R, Merlini G (2005) Clinical aspects of systemic amyloid diseases. Biochim Biophys Acta 1753: 11-22.

15. Kyle RA, Gertz MA (1995) Primary systemic amyloidosis: clinical and laboratory features in 474 cases. Semin Hematol 32: 45-59.

16. Gertz MA (2012) How to manage primary amyloidosis. Leukemia 26: 191-198.

17. Mohty D, Pibarot P, Dumesnil JG, Darodes N, Lavergne D, et al. (2011) Left atrial size is an independent predictor of overall survival in patients with primary systemic amyloidosis. Arch Cardiovasc Dis 104: 611-618. 